Recepción: 15 / 04 / 2017

Aceptación: 01 / 05 / 2017

Publicación: 15 / 05 / 2017
Ciencias Médicas

Artículo Científico

\section{Diagnostico bucal a escolares}

\author{
Oral diagnosis of schoolchildren
}

Escola de diagnóstico oral
Adriana Amado-Schneider adriana.amados@ug.edu.ec

Dalia del Barco Vazques " dalia.delbarcov@ug.edu.ec

María E. Vega-Nuques "m maria.vegan@ug.edu.ec

Correspondencia: adriana.amados@ug.edu.ec 


\section{Resumen}

El objetivo de esta investigación es determinar mediante las principales manifestaciones bucales encontradas entre los escolares que asisten a la Unidad Educativa Especializada "Manuela Espejo" de la ciudad de Guayaquil. Unidad educativa especializada exclusiva para niños con discapacidad intelectual, multidiscapacidad y autismo. Por medio de ella el Ministerio de Educación del Ecuador genera oportunidades orientadas a una inclusión educativa, familiar, social y laboral. Promueve el desarrollo integral de las personas con discapacidad para que alcancen una mejor calidad de vida. Siendo la aplicación de medidas de prevención de las enfermedades una forma de ayudar en la salud integral de este grupo de escolares necesitamos diagnosticar los principales problemas que presentan en la cavidad bucal para mejorar su calidad de vida evitando enfermedades en su boca. Este trabajo de investigación es de tipo documental, descriptivo y bibliográfico. Se utilizó la técnica del fichaje para recoger y ordenar los datos obtenidos. Se realizó previamente un análisis de revisión bibliografía en artículos científicos y libros. Se concluye que los valores altos obtenidos como índice de placa y prevalencia de caries en el presente estudio se deben a que los padres de familia o tutores responsables desconocen la forma adecuada de prevenir las enfermedades de la cavidad bucal. Los datos obtenidos en el presente trabajo de investigación servirán como Lineamiento para la elaboración de una guía de: "Técnicas de higiene para padres de niños con capacidades especiales". De esta forma aportar al mantenimiento de la calidad de vida del mencionado grupo poblacional.

Palabras clave: Minusvalía; discapacidad; placa bacteriana; caries dental; gingivitis. 


\begin{abstract}
The objective of this research is to determine by means of the main oral manifestations found among the students attending the Specialized Educational Unit "Manuela Espejo" of the city of Guayaquil. Specialized educational unit exclusively for children with intellectual disability, multidiscapacidad and autism. Through it, the Ministry of Education of Ecuador generates opportunities aimed at an educational, family, social and labor inclusion. Promotes the integral development of people with disabilities to achieve a better quality of life. Being the application of measures of prevention of the diseases a way to help in the integral health of this group of students we need to diagnose the main problems that they present in the bucal cavity to improve their quality of life avoiding diseases in his mouth. This research work is documentary, descriptive and bibliographic. The signing technique was used to collect and sort the data obtained. We performed previously a literature review on scientific articles and books. It is concluded that the high values obtained as plaque index and prevalence of caries in the present study are due to the parents or guardians responsible not knowing the proper way to prevent diseases of the oral cavity. The data obtained in the present research work will serve as a guideline for the elaboration of a guide of: "Hygiene techniques for parents of children with special abilities". In this way contribute to maintaining the quality of life of that population group.
\end{abstract}

Key words: Handicap; disability; dental plaque; dental caries; gingivitis. 


\section{Resumo}

O objetivo desta pesquisa é determinar por meio das principais manifestações orais encontradas entre os alunos da Unidade Educacional Especializada "Manuela Espejo" da cidade de Guayaquil. Unidade educativa especializada exclusivamente para crianças com deficiência intelectual, multidiscapacidad e autismo. Através dele, o Ministério da Educação do Equador gera oportunidades de inclusão educacional, familiar, social e laboral. Promove o desenvolvimento integral das pessoas com deficiência para alcançar uma melhor qualidade de vida. Sendo a aplicação de medidas de prevenção das doenças uma forma de auxiliar na saúde integral deste grupo de alunos é necessário diagnosticar os principais problemas que apresentam na cavidade bucal para melhorar a sua qualidade de vida evitando doenças em sua boca. Este trabalho de pesquisa é documental, descritivo e bibliográfico. A técnica de assinatura foi usada para coletar e classificar os dados obtidos. Realizamos anteriormente uma revisão da literatura sobre artigos e livros científicos. Conclui-se que os valores elevados obtidos como índice de placa e prevalência de cárie no presente estudo são devidos aos pais ou responsáveis responsáveis, desconhecendo a maneira correta de prevenir doenças da cavidade oral. Os dados obtidos no presente trabalho de pesquisa servirão de guia para a elaboração de um guia de: "Técnicas de higiene para pais de crianças com habilidades especiais". Desta forma, contribuem para a manutenção da qualidade de vida desse grupo populacional.

Palavras chave: Handicap; incapacidade; placa dentária; cáries dentárias; gengivite. 


\section{Introducción.}

Lograr una excelente salud bucal en pacientes con necesidades especiales representa un desafío para el profesional odontólogo, las diferentes discapacidades físicas y cognitivas limitan la adecuada eliminación de la placa dentobacteriana, ocasionando con esto el incremento de enfermedades bucales de muy alta prevalencia en la comunidad, principalmente la caries dental y la enfermedad periodontal. En este trabajo investigativo se pretende diagnosticar información las enfermedades bucales más frecuentes entre esta población escolar en condición de discapacidad con respecto a su higiene oral,

Caries dental, gingivitis, maloclusión, queilitis y hábitos son patologías que afectan a la generalidad de los individuos y más aún a los que presentan necesidades especiales. Principalmente los niños tienen mayor prevalencia de acumulación de placa bacteriana y caries debido a diversos factores que pueden ser locales o ambientales. A esto se debe que estén incluidos dentro del grupo de riesgo, ya que su cuidado e higiene personal dependen de otras personas. Es por esto que requieren mayor atención y cuidados bucales. Además, deben ser incluidos dentro de programas de prevención de salud oral.

Debido a las necesidades en estos tipos pacientes en cuanto a prevención y control de placa bacteriana se debe tener en cuenta tres puntos claves: informar, motivar y educar al paciente y sus familiares o personas responsables del cuidado. Recomendar una dieta adecuada y buena higiene a través del cepillado dental.

Algunos investigadores afirman que estos pacientes presentan mayor prevalencia de caries dental y las causas serían: menor velocidad de flujo salival, malos hábitos de higiene bucal debido a una deficiente motricidad fina y a la poca orientación de los padres o tutores en este aspecto; dietas 
cariogénicas ya que los padres complacen frecuentemente a sus niños con dulces y el uso de mayor cantidad de jarabes debido a mayor susceptibilidad a infecciones. Otro de los factores de riesgo es que los niños especiales dejan el pecho o biberón a una edad mayor; lo cual los predispone más a la enfermedad.

Los pacientes con necesidad especiales requieren de cuidados únicos para realizar su higiene de acuerdo a su edad, colaboración, nivel de incapacidad y compromiso sistémico, de lo contrario pueden desarrollar fácilmente enfermedades orales las cuales producen dolor, incomodidad y la necesidad de tratamientos largos, costosos y de dudable pronóstico, así mismo, el mal estado de salud oral es un factor de co-morbilidad cuando se asocia con una enfermedad sistémica existente

Es necesario tomar conciencia sobre la falta de información que existe hacia una correcta educación en medidas preventivas a los padres o tutores de los niños con capacidades diferentes. Saber que estamos frente a un grupo de riesgo; nos ayudará a la disminución de su incidencia. Cuando hablamos del cuidado de la salud en estos grupos de la población con capacidades especiales no solo deberíamos referirnos al personal médico u odontológico, sino involucrar al paciente y su familia para educarlos en temas de salud bucal y lograr un total entendimiento de una correcta higiene de la cavidad oral para prevenir la acumulación de placa bacteriana y diversas patologías entre ellas la caries dental.

\section{Revisión de Literatura}

Definición de discapacidad: la OMS establece en 1980 que las personas con discapacidades pueden presentar: deficiencias, discapacidades o minusvalías. Al definir estos 3 términos nos dice: la deficiencia es la exteriorización directa de las consecuencias de la enfermedad y se manifiesta tanto en órganos del cuerpo como en sus funciones (incluidas psicológicas); la discapacidad es la 
objetivación de la deficiencia en el sujeto y con una repercusión directa en su capacidad de realizar actividades en términos considerados normales para cualquier sujeto de sus características (edad, género) y la minusvalía es la socialización de la problemática causada en un sujeto por las consecuencias de una enfermedad, manifestada a través de la deficiencia y/o la discapacidad, afectando el desempeño del rol social propio. Así pues, dentro de la salud: la deficiencia es toda pérdida o anormalidad de una estructura o función psicológica, fisiológica o anatómica, la discapacidad es toda restricción o ausencia (debida a una deficiencia) de la capacidad de realizar una actividad en la forma o dentro del margen que se considera normal para un ser humano y la minusvalía es una situación desventajosa para un individuo. (García \& Sánchez, 2000)

A su vez las deficiencias se clasifican en: deficiencias físicas, deficiencias mentales y deficiencias sensoriales.

Discapacidad en el Ecuador: según la base de datos del Consejo Nacional para la igualdad de capacidades CONADIS, 2015 existen 408.021 personas con discapacidad y en la provincia del Guayas 96.339, de los cuales solo 13.450 reciben educación especial completa según los datos del Ministerio de Educación del Ecuador.

En el 2011 la Organización Mundial de la Salud (OMS) publicó que las personas con discapacidad reciben a menudo una atención sanitaria insuficiente. La mitad no puede costear los servicios de salud, reciben un mal trato e incluso se les niega la atención tanto de salud general como de salud bucal. El $80 \%$ de ellas vive en países de bajos ingresos, la mayoría son pobres y no tienen acceso a servicios básicos ni a servicios de rehabilitación.

En la actualidad existe una alta índice de personas con discapacidades con el deseo de mejorar la salud y el bienestar bucal. Por lo que es importante conocer el protocolo para cubrir 
todas estas necesidades. Una de las mejores maneras de hacerlo es comprender la incidencia y la prevalencia de las enfermedades en la población. (De la Teja-Ángeles, Durán-Gutiérrez, EspinosaVictoria, \& Ramírez-Mayans, 2008)

Las personas con necesidades especiales en su salud general necesitan más atención por parte de las personas responsables de su cuidado, en lo referente a la higiene de su cavidad bucal en la mayoría de las situaciones la persona con discapacidad no puede realizarla de forma correcta por sí misma, necesitando ayuda específica según el tipo de discapacidad que presente, las patología bucales más frecuentes son caries dental, enfermedad periodontal, necrosis pulpar, pérdida prematura de piezas temporales, entre otras, siendo las mismas que se observan en toda persona que no realice cuidados diarios para prever enfermedades bucales, por lo que se eligió este tema de investigación para conocer el protocolo de atención en estos pacientes y así cuidar en ellos la salud de su cavidad bucal para mejorar su calidad de vida (De la Teja-Ángeles, Durán-Gutiérrez, Espinosa-Victoria, \& Ramírez-Mayans, 2008).

Nivel de discapacidad: el reconocer el nivel de discapacidad que presente el niño o adolescente por parte del profesional odontólogo nos ayudará al momento de brindarle al paciente la atención odontológica determinará las destrezas que desarrolle el individuo. En nuestra profesión nos interesa conocer del paciente el nivel de capacidad que tiene para lograr: la comunicación, el cuidado personal, las habilidades sociales-interpersonales, la adaptación a la vida la socialización en el hogar, el uso de recursos de la comunidad, las habilidades académicas, funcionales y como adulto el trabajo-ocio y la seguridad. 
Los individuos con deficiencia de inteligencia, son los que interesan al odontólogo puesto que pueden requerir de orientación especial de la conducta. Se especifican cuatro grados de severidad del retraso mental:

Leve: cuando el individuo es educable. Es grupo comprende el $85 \%$ de personas con retraso mental, desarrollan habilidades sociales y de comunicación en los años preescolares, con el apoyo adecuado pueden vivir exitosamente en la comunidad como adultos.

Moderado: se conoce como entrenable, constituyen el 10\%. Se benefician del entrenamiento vocacional y pueden atender a su cuidado personal con supervisión moderada, con apoyo y la supervisión. Se adaptan bien a la vida en la comunidad.

Severo: alrededor del 3 al 4\%. Pueden ser capaces de realizar tareas sencillas, entornos compatibles y adaptarse a la vida en comunidad, como a un grupo de hogar o a un entorno familiar, a menos que tengan una discapacidad agravante asociada, que demande atención especial

Profundo: del 1 al 2\%. Tienen trastorno neurológico identificable que representa la enfermedad. De muy difícil adaptación a su entorno social. (Majluf \& Vasquez Palomino, 2014)

Desarrollo de la motricidad: la motricidad es la acción del sistema nervioso central que determina la contracción muscular. Los hábitos de higiene se ejecutan con el desarrollo de la motricidad gruesa ya que realizan movimientos grandes como: bañarse, cepillarse el cabello, etc.

Sin embargo, el cuidado dental depende del desarrollo de motricidad fina. Intervienen factores de coordinación motora y procedimientos coordinados. La muñeca, la palma de la mano y los dedos pulgar e índice son fundamentales en la realización de todos los movimientos, también los otros dedos medio, anular y meñique juegan un papel importante de apoyo ya que, sin la 
coordinación muscular de estos, junto con el apoyo de la mano sobre el soporte, se hace difícil el control de un movimiento, son estas dos las causas importantes en su dificultad para su aseo dental. (Patricia Rodriguez, Susana Flores, 2013)

Los niños con síndrome de Down, por ejemplo, en su mayoría tienen problemas visuales y de hecho un 3\% presenta cataratas densas y glaucoma. Por tanto, habrá dificultad para la coordinación viso-motriz. También presentan hipotonía muscular debido a la perdida de ligamentos. Lo que se traduce en flacidez y torpeza de movimientos. (Munoz, 2004)

Dificultades para realizar la higiene de la cavidad bucal: al hablar de las dificultades que tienen los niños con capacidades especiales al momento de realizar su higiene personal debemos considerar que en todo niño hay dos problemas: el tratamiento del síndrome que padece y la adaptación social de su personalidad global.

Desde el modelo pedagógico DIR debemos evaluar al individuo: D (desarrollo) consiste en entender la etapa de desarrollo socio-emocional o "funcional" en que se encuentra el niño/a, I (individualidad) consiste en entender las diferencias individuales que cada niño posee, $\mathrm{R}$ (relaciones) consiste en entender los patrones relacionales que afectan la interacción del niño/a con sus padres o cuidadores significativos, aspecto que juega un rol clave para tener oportunidades de organizar los instrumentos del desarrollo al servicio de conductas comunicativas cada vez más complejas. (Breinbauer, 2006)

A nivel físico y como alteraciones en su desarrollo podríamos resumir las dificultades que presentan los niños con capacidades especiales en:

- Alteraciones de la visión 
- Déficit viso motriz

- Falla en el desarrollo de su motricidad fina

- Hipotonía muscular

- Alteraciones anatómicas propias de sus cuadros clínicos.

Los niños con capacidades especiales muestran miedos y fobias muy similares a los niños de su edad. Se habla de miedos basados en experiencias vividas. Sin embargo, niños con autismo, por ejemplo, presentan especial rechazo a los ruidos fuertes. Lo que causaría una gran dificultad si los padres le compran por indicación del profesional un cepillo eléctrico. Y más aún en la visita al consultorio odontológico para la limpieza rutinaria. (Baidal, 2016)

A su vez este conjunto de personas tiende a presentar problemas periodontales, lo que a nivel psicológico se traduce en "no me cepillo porque le tengo miedo a la sangre". Los apiñamientos también son una característica predominante y nada beneficiosa cuando se trata de mantener libres de placa a las piezas dentales. (Zaman, 2007)

La dieta de ellos, por sus dificultades para comer solos o deglutir tiene altas cantidades de carbohidratos y sustratos blandos. Esto se convertirá en una amenaza para la protección de las piezas dentales. Estas evaluaciones alertan a los odontólogos de que el niño necesita desde edades tempranas un enfoque individualizado en el consultorio odontológico. (Rojas y Fernández, 2009)

El medio ambiente es un factor crucial en el desarrollo del ser humano. Cada niño tiene un temperamento característico desde la edad más temprana. Los psicólogos, han resaltado la influencia del medio ambiente. La personalidad se desarrolla por la naturaleza (influencia genética) o por la crianza (influencia ambiental). Si ambas están en armonía se puede esperar un desarrollo 
saludable del individuo, de lo contrario vendrán los problemas de comportamiento. (Rosales C, y otros, 2013)

Estudios realizados en personas con retardo mental describen cambios y manifestaciones clínicas orales frecuentes como: pigmentaciones, gingivitis crónica generalizada, cálculos, enfermedad periodontal severa, pérdida ósea y pérdida prematura de dientes, aumentando su incidencia y severidad por el difícil acceso a los servicios de salud de este grupo de personas. (Marulanda, Betancur, Espinoza, Gómez, \& Tapias, 2011)

Un estudio realizado por Reuland-Bosma demostró que los adolescentes con síndrome de Down tienen mayor prevalencia de actinobacillus actinomycetemcomitans comparados con adolescentes sanos. Del mismo modo, se ha demostrado que la caries dental es una enfermedad de alta prevalencia en esta población y está relacionada con la severidad de la discapacidad, pues los pacientes con discapacidad leve generalmente presentan porcentajes más bajos de caries dental cuando se comparan con los que presentan discapacidades moderadas y severas, los cuales presentan índices de caries superiores. (Marulanda, Betancur, Espinoza, Gómez, \& Tapias, 2011)

Las dificultades físicas que puedan presentar son obra de la naturaleza la gran mayoría del grupo en el que nos estamos fijando en este estudio no realiza por si solo procedimientos de higiene bucal, necesita de su tutor. Establecer que está en una relación de dependencia: "es el estado de carácter permanente en que se encuentras las personas que, por razones derivadas de la edad, la enfermedad o la discapacidad y ligadas a la falta o a la pérdida de autonomía física, mental, intelectual o sensorial, precisan de la atención de otra u otras personas o ayudas importantes para realizar actividades básicas de la vida diaria o, en el caso de las personas con discapacidad 
intelectual o enfermedad mental, de otros apoyos para autonomía personal." (Perez, Limeres, \& Fernandez, 2012)

Aparecen nuevas dificultades, entra en juego la relación tutor-niño: la cercanía que puedan tener entre ellos es lo que le va a permitir dejar que otra mano se acerque a su boca sin causar ninguna reacción negativa, el ambiente en el que se dará la higiene bucal: es posible que factores como la luz o los colores influyan en la calma del niño favoreciendo o no la técnica de cepillado. (Zaman, 2007)

El instrumental a utilizarse: es necesario que desde pequeño se le presente el cepillo la pasta y el hilo dental como aliados. La dificultad con los instrumentos de aseo es la percepción de ellos como objetos peligrosos y por ende causan miedo. La persona a cargo es la responsable de camuflarlos y volverlos atrayentes. (Perez, Limeres, \& Fernandez, 2012)

El tiempo que le tome realizarlo: la mayoría de estos niños y jóvenes son muy impacientes y cuidan mucho de su espacio personal. Por lo que un cepillado minucioso que tome tiempo para ellos se volverá una dificultad. (Boyer-Chu, 2007)

Si tuviéramos que mencionar a manera de recapitulación las razones por las que se dificulta la higiene dental en estos niños a nivel psicológico sería importante para los profesionales de la salud bucal recordar los principales factores que la dificultan:

- Por sus miedos y fobias

- Por la desconfianza que pueda producir quien lo ayuda

- Por el ambiente en que se realiza el aseo personal

- Por el instrumental a utilizarse 
- Por el tiempo que se tome en aplicar los procedimientos de higiene.

Manifestaciones bucodentales en los pacientes especiales: entre las principales se deben mencionar las siguientes:

Caries dental: producida por la falta de higiene, el tipo de dieta que muchas veces tienen estos pacientes y a la falta de visitas a la consulta odontológica. Es la patología más prevalente en las poblaciones de pacientes con discapacidad, especialmente en los grupos de pacientes ciegos, sordomudos y con parálisis cerebral (Manzano, 2010)

Enfermedad Periodontal: es considerada como una patología infecciosa crónica y multifactorial donde causa una destrucción de los tejidos de soporte de las estructuras del diente. El desarrollo de la enfermedad periodontal se inicia por la retención de placa dental, pero existen factores de riesgo de tipo inmunológico, hormonal y celular que pueden llevar a una evolución más rápida o agresiva. Los pacientes que padecen algún tipo de discapacidad, tienen una predisposición mayor a desarrollar enfermedad periodontal, como en el caso del síndrome de Chediak-Higashi, el Síndrome de Down y el Síndrome de Papillon-Lefevre. (Nualart-Grollmus, Morales-Chavez, \& Silvestre-Donat, 2010)

Maloclusiones: existen diversas determinaciones genéticas que favorecen el desarrollo de maloclusiones. En los pacientes con discapacidades físicas y psíquicas existen múltiples hábitos como la respiración bucal, la succión digital y la interposición lingual. Debido a la falta de masticación adecuada en estos pacientes se presenta apiñamiento dentario, pacientes con Parálisis Cerebral Infantil desarrollan mordidas abiertas anteriores severas por la alteración existente a nivel del hipogloso o XII par craneal que se encarga de coordinar los movimientos de la lengua. Por otro parte, los niños con Síndrome de Down presentan maxilares hipoplásicos, con la consecuente 
disminución en el desarrollo del paladar y mandibular hiperplásicas por el descenso de la lengua, dando origen a maloclusiones Clase III de Angle, donde la mandíbula se ubica por delante del maxilar superior. (Lewis M, 2011)

Autolesiones: son actos de autoagresión que tiene como resultado un daño a nivel de los tejidos. Los pacientes con necesidades especiales presentan autolesiones entre el 7.7 y 22.8 , sin discriminación de sexo. Las conductas de autoagresión tienden a manifestarse en desórdenes del desarrollo como el retardo mental y el autismo; desórdenes psiquiátricos como el obsesivo compulsivo, la anorexia, la esquizofrenia y el desorden dismórfico corporal. Algunos autores manifiestan que existe una relación significativa entre la presencia y severidad de la conducta de autoagresión y la presencia de pobres habilidades intelectuales, comportamientos repetitivos anormales, desórdenes del movimiento o del sueño. Estas pueden obtener un origen neurológico, biológico o psicológico y el paciente suele golpearse o morderse distintas parte del cuerpo, tales como las manos, cara y mandíbula (Lewis M, 2011)

Halitosis (mal aliento, mal olor bucal): puede ser por causas extraorales (alteración del tracto superior e inferior), algunas enfermedades sistémicas, alteraciones metabólicas, medicaciones y carcinomas, en aproximadamente el $90 \%$ de los casos de halitosis tienen sus orígenes en causas intraorales que son biofilm lingual, enfermedades periodontales, lesiones cariosas profundas, necrosis pulpares expuestas, pericoronaritis, prótesis dentales mal higienizadas, etc.

Bruxismo: es una actividad parafuncional oral que consiste en el apriete y rechinamiento dentario, es de origen multifactorial y está ligado principalmente al stress y a las alteraciones del sueño. De acuerdo a las características clínicas, se manifiestan diferentes tipos de bruxismo asociándose principalmente con adultos y aunque se presenta en menor porcentaje en niños 
generalmente cuando viven situaciones de stress a las que no se les pone atención, se debe diferenciar del desgaste fisiológico. (Frugone Zambra \& Rodríguez , 2003)

Xerostomía: se caracteriza por la sequedad de la boca causada por disminución o ausencia de la secreción salival. Por si misma no es una enfermedad, sino un síntoma que se presenta en diferentes condiciones patológicas, ya sea como efecto secundario a la radiación de la cabeza y cuello, a la ingesta de algunos medicamentos o a la disminución de la función de las glándulas salivales aunque se presenta escasamente en niños, se debe diferenciar del desgaste fisiológico. (Frugone Zambra \& Rodríguez , 2003)

Babeo: también llamado incontinencia salival normalmente se asocia a una disfunción de la actividad motora oral, a una incapacidad para tragar, a un déficit de esfínter oral y con menor frecuencia a un incremento de la producción de saliva (hipersalivación) es un problema bastante frecuente en personas discapacitadas (parálisis cerebral, retraso mental, epilepsia, enfermedad de Párkinson, esclerosis lateral amiotrófica, etc.) que conlleva importantes repercusiones físicas, psicosociales, y estéticas.

\section{Protocolo de prevención de enfermedades bucales para pacientes pediátricos con} necesidades especiales: los niños que presentan necesidades especiales generalmente tienen las mismas necesidades básicas de cuidado dental que todos los demás niños, incluyendo cepillarse los dientes al menos dos veces al día supervisado por un adulto, pasarse el hilo dental una vez al día, y visitar con regularidad al odontólogo, iniciando desde el 1er año de edad.

Consejos importantes para prevenir los problemas dentales en la infancia, incluyen: 
- La limpieza bucal puede hacerse con una gasa estéril que el padre/madre pueda introducir en la boca del niño, con la que se procede a frotar los dientes y partes blandas de la cavidad con el fin de retirar los residuos de comida acumulados en la boca.

- Entre los seis meses y los dos años, se puede utilizar un cepillo dental del tamaño adecuado.

- Prevenga la caries por causa del biberón: no permita que su bebé se quede dormido durante la toma de su leche o jugo en el biberón.

- Deshabituar a su niño del biberón a una edad correcta.

- Asegúrese de que su niño tenga y mantenga una dieta sana, que incluya el suficiente calcio para tener dientes fuertes.

- Limite la ingesta de meriendas no saludables (alimentos con mucha azúcar o grasa).

- También consulte con un odontólogo sobre el uso de flúor para los niños y la edad apropiada para que su niño comience a usar un dentífrico/pasta dental. (Christianson, 2009)

- De acuerdo con la Academia Americana de Odontología Pediátrica AAPD (2011), se recomienda iniciar un buen cuidado dental desde que el bebé nace, limpiando las encías diariamente con un cepillo de dientes suave para niños o con un paño mojado con agua. Si su bebé se acostumbra a la terapia de que le laven las encías o dientes, es muy probable que colabore de forma más positiva con el cuidado dental cuando crezca.

- Un adulto debe ser responsable de ayudar a cepillar los dientes del niño hasta que tenga seis o siete años, ya que los niños pequeños, y aquellos con retrasos motrices, no cuentan con la suficiente destreza para cepillarse efectivamente los dientes. Los niños con retrasos motrices 
o intelectuales, suelen continuar necesitando la ayuda o supervisión de los padres para lavarse los dientes o pasarse el hilo dental luego de la primera infancia, durante su niñez, su adolescencia y su etapa de adultos. En otras palabras siempre van a depender de otras personas para su correcta higiene. A continuación listamos algunos consejos para que su niño coopere con el cepillado de dientes:

- Permita que él/ella elija su propio cepillo de dientes en la tienda de abastos. Es más posible que él/ella colaboren con el cepillado si le gusta el cepillo de dientes.

- Modele excelentes rutinas de cepillado para su niño, describa lo que usted está haciendo mientras se cepilla los dientes. Las investigaciones indican que los hijos de padres con una muy práctica higiene dental mantienen tasas más bajas de caries dentales. Túrnese con el niño mientras se lavan los dientes.

- Permita que su niño se sienta más seguro mientras le cepilla los dientes, sentándolo en sus piernas cuando lo realice. Este abordaje, incluso le permite observar mejor la boca del niño. Si es posible, utilice un cepillo de dientes eléctrico para cepillar los dientes de su niño. Convierta el cepillarse los dientes en un juego, cante canciones mientras le cepilla los dientes o colóquese frente a un espejo.

- Modele el cepillado de dientes en una muñeca o animal de peluche y deje que el niño practique el cepillando los dientes. Esto puede ayudar si su niño siente ansiedad con respecto a ponerse el cepillo de dientes en la boca. (Cassy Christianson, 2009) 
No debemos olvidar la importancia de las visitas periódicas al odontólogo, para que este profesional de la salud, sea el que al revisar la cavidad bucal y detectar algún problema de salud desde etapas iniciales, además será el encargado de elaborar el mejor protocolo de atención individualizado a las necesidades del paciente de acuerdo a su capacidad de cooperación y deberá responsabilizar a los padres o tutores sobre su participación activa responsable en la prevención de enfermedades de la cavidad bucal.

\section{Metodología.}

Se realizó un estudio epidemiológico, descriptico y transversal entre los niños y adolescentes que asisten a clases en la Unidad de Educación Especializada "Manuela Espejo", ubicada en las instalaciones del colegio fiscal Vicente Rocafuerte, ubicado en la ciudad de Guayaquil, en las calles Vélez y Lizardo García, perteneciente a la parroquia urbana Urdaneta.

La población de estudio fueron los 340 escolares de la Unidad Educativa Especializada "Manuela Espejo" tanto de la jornada matutina como vespertina, donde sus estudiantes presentan discapacidad intelectual, multidiscapacidad y autismo. Cuenta con una planta de 42 profesionales entre docentes, psicólogos educativos y clínicos; terapistas físicos, de lenguaje y ocupacionales. En el área física la institución cuenta con 15 aulas para el desarrollo de conocimientos funcionales, áreas de intervención física y temprana, de lenguaje y sicología, aula hogar para aprender habilidades de la vida diaria, talleres de manualidades, horticultura, 6 comedores, áreas recreativas y administrativas donde los niños y adolescentes con discapacidad y sus familias encuentran un lugar que les brinda un servicio de educación de calidad y con calidez. 
Nuestro agradecimiento a las autoridades y personal docente y administrativo de la Unidad Educativa Especializada "Manuela Espejo por la apertura para la realización del presente trabajo de investigación, en beneficio de los niños y adolescentes con necesidades especiales.

Se elaboró una solicitud dirigida a las autoridades de la Unidad Educativa Especial Fiscal Manuela Espejo, a través de un oficio dirigido a la directora de la institución para realizar el trabajo de investigación. Luego se procedió hacer el examen clínico de los niños dentro del aula de clases con luz artificial, utilizando un espejo bucal y un explorador para observar las diferentes anomalías que presentan estos niños en su cavidad bucal, toda la información obtenida del examen se lo anotó en una hoja de cálculo de Excel diseñada para esta investigación y luego se procedió a tabular los resultados a través de una distribución de frecuencias y porcentajes en correspondencia con los objetivos planteados.

Se escogió una muestra 175 escolares entre aquellos cuyos padres de familia firmaron el consentimiento informado aceptando participar en el estudio, asistieron a clases el día de la revisión, no presentaban problemas de salud y colaboraron en la revisión de su cavidad bucal.

Esta entidad educativa presta servicios a niños y adolescentes del sector norte de la ciudad que habitan en Monte Sinaí, Bastión, Prosperina, Mapasingue, vía a Daule, entre otros. Por estar en época climática de temporada de lluvias al momento de la realización de la investigación se notó bastante ausentismo de niños y adolescentes a sus actividades educativas, los madres manifestaban que se les dificultada la movilización además de presentar cuadros de enfermedades respiratorias que necesitaban reposo para mejorar la salud.

Los datos fueron recogidos por estudiantes de la Facultad de Odontología de la Universidad de Guayaquil, pertenecientes a Quinto Año, paralelo 3, en el periodo lectivo 2015-2016 que 
realizaron una brigada de Vinculación con la Comunidad en la respectiva unidad educativa, donde dieron una atención del nivel 1 de prevención entre los escolares y sus padres de familia.

Agradecemos también la colaboración de la estudiante de la Facultad de Odontología de la Universidad de Guayaquil, perteneciente a Quinto Año, paralelo 10, en el periodo lectivo 20152016, Christelle López R. por su aporte al presente estudio con la tesis "Manifestaciones Bucales en niños con necesidades especiales" realizada en la misma unidad educativa y también a la estudiante de la Facultad de Odontología de la Universidad de Guayaquil, perteneciente al VII semestre, del periodo académico I-2016 por su participación como coautora del artículo científico "Prevalencia de caries e índice de placa bacteriana en Unidad Educativa Especializada Manuela Espejo, Guayaquil, 2015-2016.

La muestra fue representada por niños y adolescentes tanto de género masculino como de género femenino y cuyas edades estaban entre los 4 años y los 19 años de edad. Se llenó una hoja de recolección de datos con la técnica del fichaje, donde se utilizó la Historia Única de Odontología o formulario 0,33 del M.S.P. Se procedió a la tabulación de datos por medio del programa Excel para la obtención de los resultados. Se analizó la prevalencia de caries, el índice de CPO-ceo y el índice de placa bacteriana.

\section{Resultados}

Análisis de la muestra por género: al analizar la muestra que fue de 175 escolares de la Unidad de Educación Especializada "Manuela Espejo" de la Ciudad de Guayaquil, tanto de la jornada matutina como de la jornada vespertina por género, nos dio como resultado que 103 escolares eran de género masculino que corresponden al 58,86\% y 72 escolares del género femenino que corresponden al $41,14 \%$. 


\begin{tabular}{|c|c|c|}
\hline \multicolumn{2}{|c|}{ MUESTRA POR GÉNERO } \\
\hline femenino & 72 & $41 \%$ \\
\hline masculino & 103 & $59 \%$ \\
\hline TOTAL & $\mathbf{1 7 5}$ & $\mathbf{1 0 0 \%}$ \\
\hline
\end{tabular}

Tabla $N^{\circ}$ 1.- Distribución de muestra por género

Análisis de la muestra por edad: al distribuir los escolares por grupos por edades, se lo realiza de acuerdo a la clasificación dada en la ficha 0,33 del MSP los más representativos fueron los escolares que se encontraban entre las edades de 10 a 14 años de edad representado por 71 escolares que corresponden al 40,57\% de la muestra y el grupo de 5 a 9 años de edad representado por 70 escolares que corresponden al $40 \%$ de la muestra, seguido del grupo de 15 a 19 años de edad representado por 30 escolares que corresponden al $17 \%$ y por último el grupo de 1 a 4 años de edad representado por 4 escolares que corresponden al $2 \%$. 


\begin{tabular}{|l|l|l|}
\hline \multicolumn{2}{|l|}{ MUESTRA POR EDAD } \\
\hline 1 a 4 años & 4 & $2 \%$ \\
\hline 5 a 9 años & 70 & $40 \%$ \\
\hline 10 a 14 años & 71 & $41 \%$ \\
\hline 15 a 19 años & 30 & $17 \%$ \\
\hline TOTAL & 175 & $100 \%$ \\
\hline
\end{tabular}

Tabla $N^{\circ}$ 2.- Muestra por grupos de edad; distribución de muestra por grupos de edad

Análisis de muestra por distribución de las anomalías bucales encontradas: del total de la muestra estudiada entre las anomalías encontradas la que presentó mayor prevalencia fue la caries dental presente en 163 escolares lo que corresponde a una prevalencia de caries del 93\%, en segundo lugar se encontró la gingivitis presente en 161 escolares lo que corresponde a una prevalencia del 92\%, seguido de la maloclusión dental presente en 156 escolares lo que corresponde a una prevalencia de mal oclusión del $89 \%$, encontrando luego la presencia de hábitos bucales en 128 escolares lo que corresponde a una prevalencia de malos hábitos del $73 \%$, seguido de la halitosis presente en 79 escolares correspondiendo a una prevalencia del $45 \%$, seguido del babeo presente en 66 escolares dándonos una prevalencia del 38\%, seguido de las autolesiones encontradas en 21 escolares correspondiendo a una prevalencia del $12 \%$ y en último lugar 
encontramos la fluorosis presente en 19 escolares representando una prevalencia del seguido del $11 \%$.

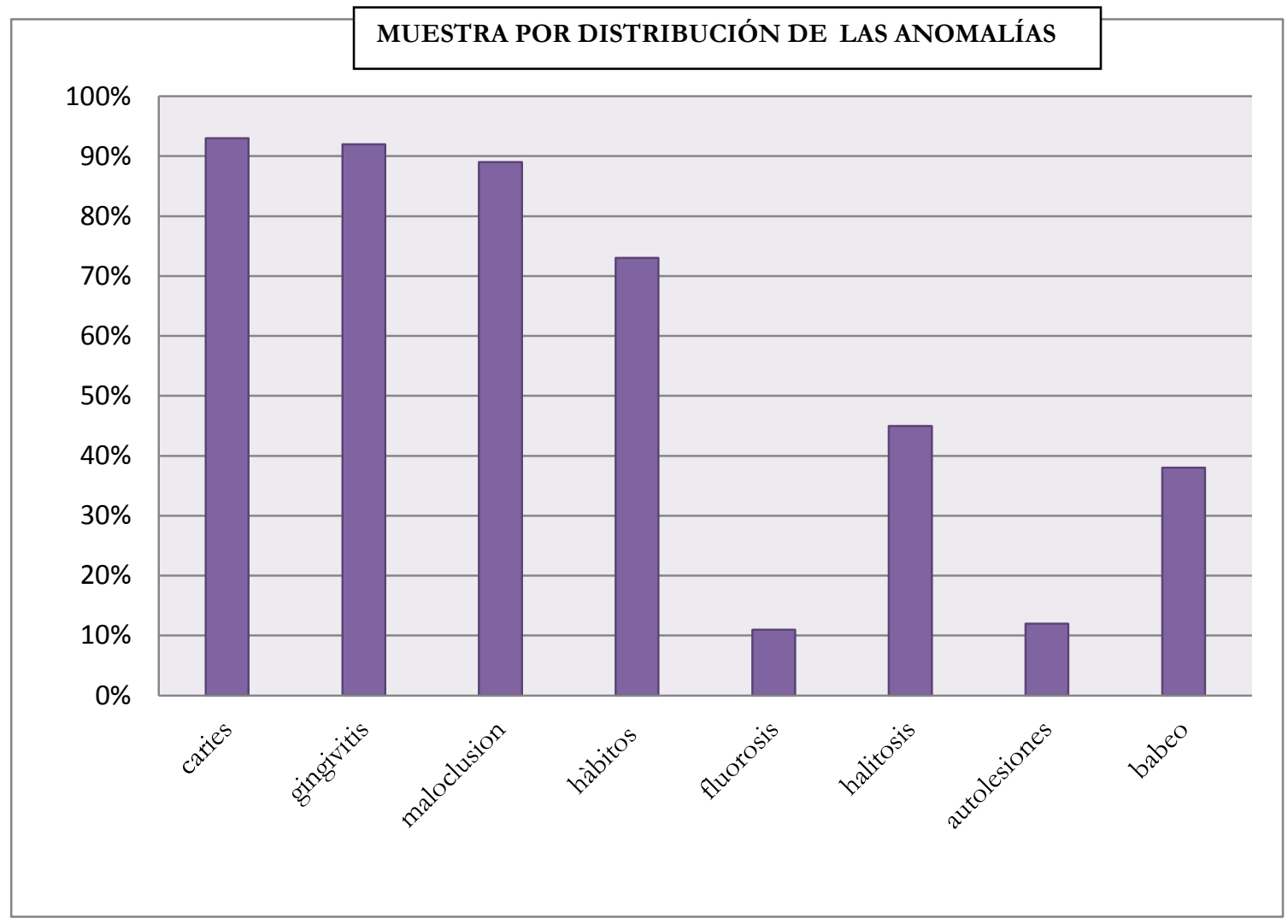

Gráfico $N^{\circ}$ 1.- Muestra por distribución de las anomalías bucales; porcentaje de anomalías bucales 
Prevalencia de caries dental: en el presente estudio se obtuvo una prevalencia de caries muy alta con un valor del $93,14 \%$ de prevalencia de caries, representada por 163 escolares con caries. Y solamente un 6,86\% de escolares no presento caries en su cavidad bucal, lo que corresponde a 12 escolares, sin presencia de caries.

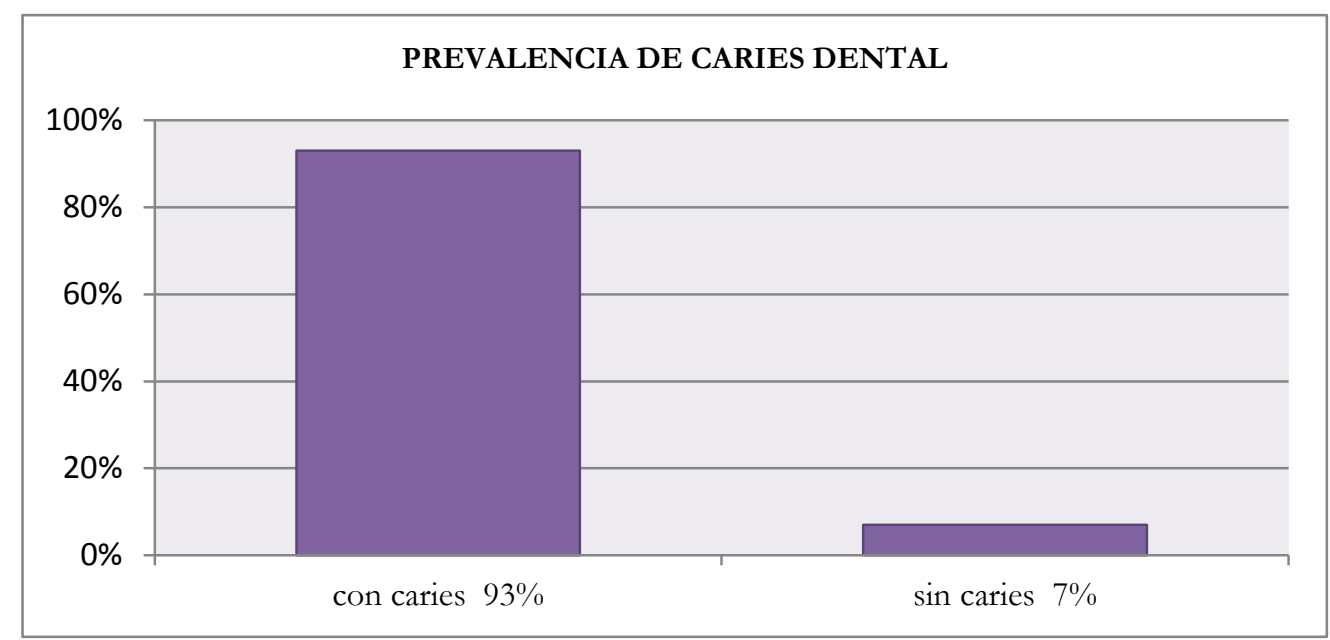

\section{Gráfico $N^{\circ}$ 2.- Prevalencia de caries dental; prevalencia de caries dental}

Prevalencia de Gingivitis: al analizar la prevalencia de gingivitis entre los escolares se obtuvo un valor de prevalencia del $92 \%$ considerado muy alto observado en 161 escolares con presencia de placa bacteriana y solamente un 8 de escolares sin gingivitis valor dado por 14 escolares con un nivel 0 de placa bacteriana. 


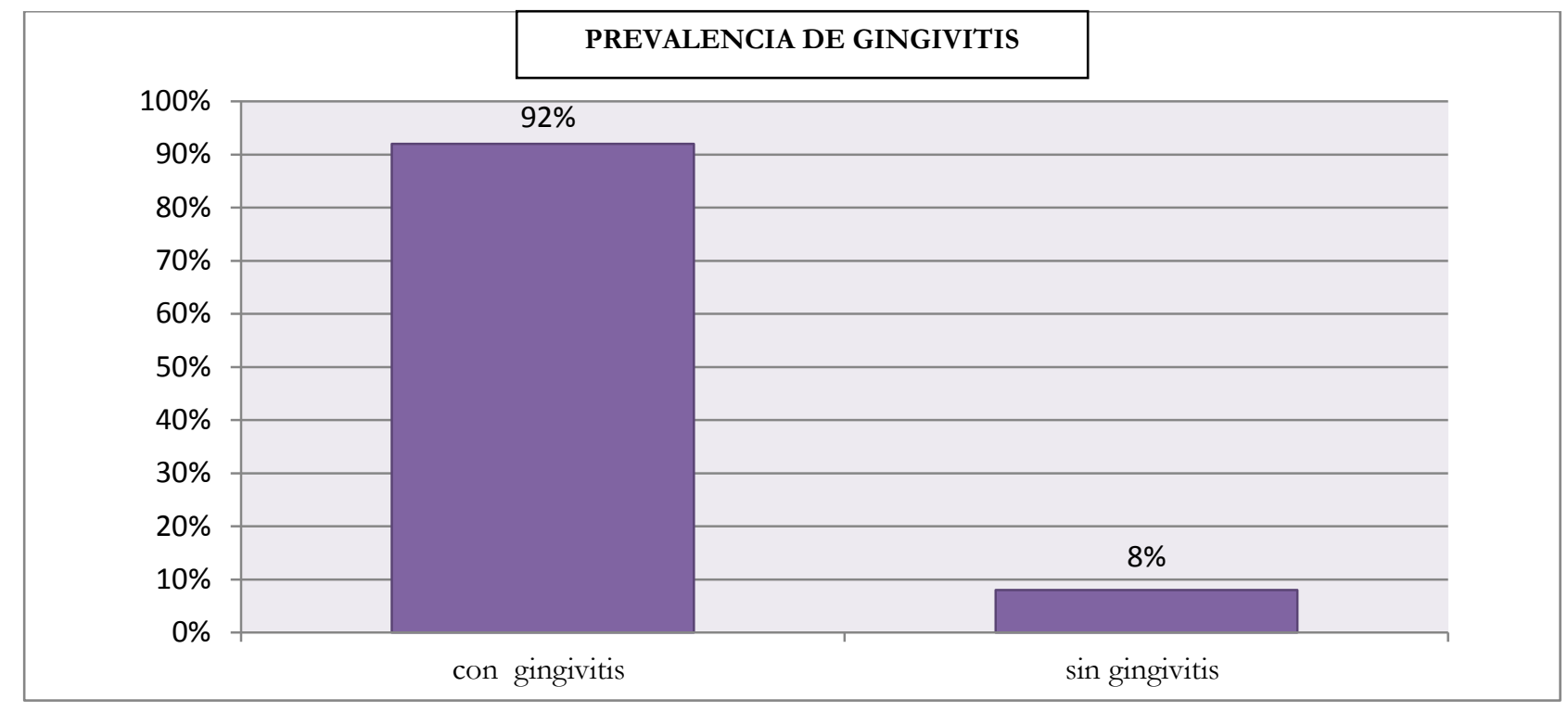

\section{Gráfico $N^{\circ}$ 3.- Prevalencia de Gingivitis; prevalencia de gingivitis}

Prevalencia de maloclusión dental: al analizar la prevalencia de maloclusión dental entre los escolares se obtuvo un valor de prevalencia del 89\% considerado muy alto observado en 156 escolares con presencia de problemas de maloclusión dental y solamente un $11 \%$ de escolares sin maloclusión dental valor dado por escolares 16 escolares que no presentaron esta anomalía bucal.

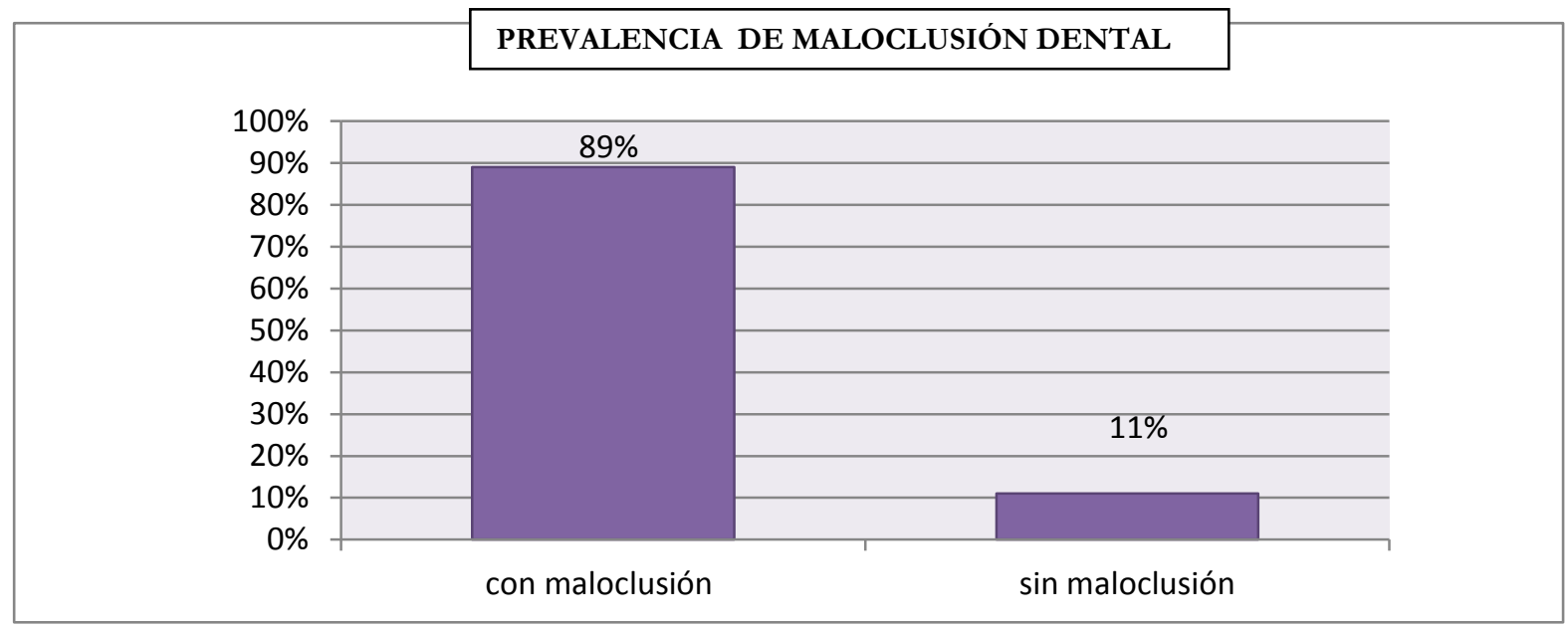

Gráfico $N^{\circ}$ 4.- Prevalencia de Maloclusión dental; prevalencia de Maloclusión dental 
Prevalencia de malos hábitos bucales: al analizar la existencia de malos hábitos bucales entre los escolares se obtuvo un valor de prevalencia del $73 \%$ al ser observados en 128 escolares y solamente un $27 \%$ de los escolares de la muestra no presento malos hábitos bucales valor dado por escolares 47 escolares que no presentaron esta anomalía bucal.

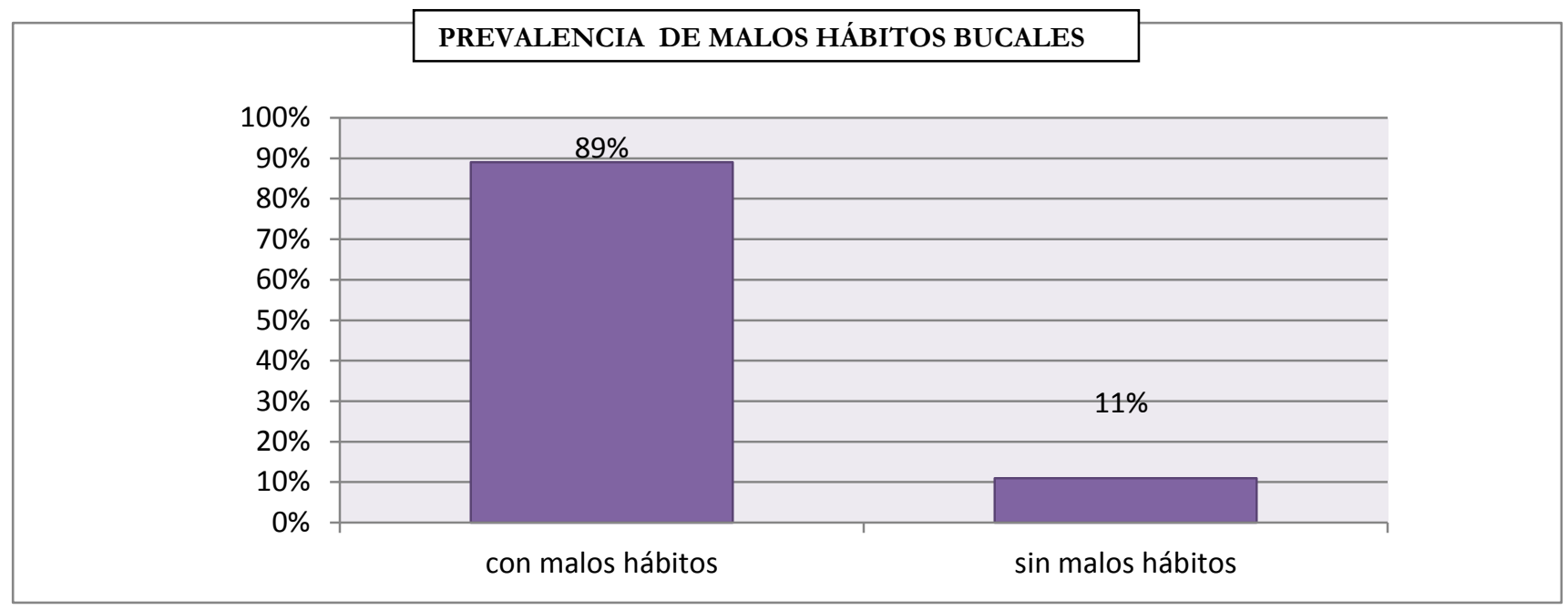

\section{Gráfico $N^{\circ}$ 5.- Prevalencia de malos hábitos bucales; prevalencia de malos hábitos bucales}

Análisis de los principales hábitos bucales: entre los principales hábitos encontrados al analizar la muestra de 175 pacientes observamos que el hábito más frecuente fue la interposición lingual observada en el $48 \%$ de la muestra representada por 84 escolares, seguido de un porcentaje similar para el hábito de onicofagia observado entre un $41 \%$ de la muestra que corresponde a 72 escolares, luego encontramos como siguiente hábito la succión digital en un 33\% de la muestra que corresponde a 58 escolares, seguido del hábito de succión labial observado en un $27 \%$ lo que corresponde a 47 escolares, luego encontramos el hábito de morder objetos en un 19\% de la muestra representado por 33 escolares y por último el hábito menos frecuente fue el del bruxismo observado solamente en un $11 \%$ de la muestra representado por 19 escolares. 


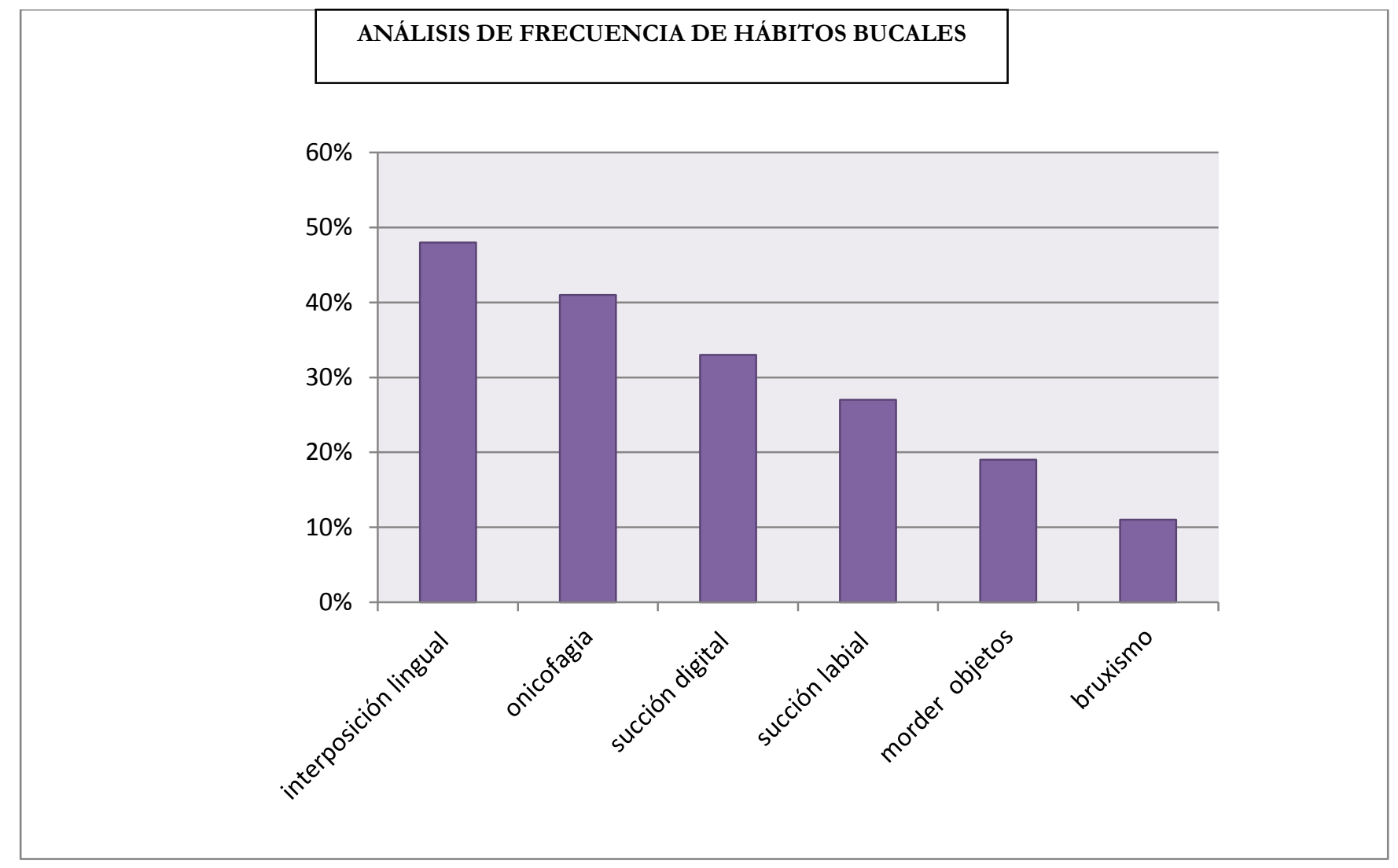

Gráfico $N^{\circ}$ 6.- Análisis de frecuencia hábitos bucales; análisis de frecuencia hábitos bucales

\section{Discusión y conclusiones.}

Los resultados obtenidos al analizar la población escolar con discapacidad entre las edades de 4 a 19 años nos revelan una alta prevalencia de anomalías en la cavidad bucal, se observó la presencia de caries, gingivitis, mal oclusión y malos hábitos bucales y en menor porcentaje pero sin restarle importancia por el porcentaje que lo representa encontramos anomalías como halitosis bucal, babeo siendo las que están presentes en menor porcentaje las autolesiones y la fluorosis dental.

Al analizar la anomalía de caries dental, el valor de prevalencia de la misma fue de $93 \%$ considerado muy alto si lo comparamos la prevalencia de caries obtenida en el estudio realizado en 
Venezuela, en la Universidad de los Andes (ULA), en Mérida por Serrano y Tolleres en el 2010, quienes analizaron la cavidad bucal de 51 niños y niñas escolares con discapacidad intelectual cuyas edades fueron entre 5 y 14 años y obtuvieron una prevalencia de caries del 55,4\%. (Tolleres, 2010)

Si comparamos con los mismos autores la prevalencia de gingivitis en nuestro estudio fue del 92\% siendo mayor que la obtenida en Mérida-Venezuela por los autores mencionados en el párrafo anterior que fue del $86 \%$.

Al analizar la prevalencia de caries obtenida en la Cuidad de Cuenca (Ecuador) en el 2014 en el trabajado de investigación realizado por Ochoa y Valarezo, donde se analizó la cavidad bucal de 130 escolares de 6 a 11 años de edad, que asistían al Centro Educativo NOVA, y Liceo Decroliano y cuyo resultado fue de una prevalencia de caries del 80\%. Es decir, estaba presente en 103 escolares, la obtenida en el presente estudio fue mayor, con un valor de $93 \%$ al estar presente en 163 escolares.

Si analizamos los malos hábitos bucales el más frecuentes observados en esta investigación fue la interposición lingual en un $48 \%$ de la muestra si lo comparamos con el estudio realizado por Narváez Sierra, María Fernanda y colaboradores en la Facultad de Odontología Universidad Cooperativa de Pasto - Colombia en el 2010 donde ellos encontraron como hábito más frecuente la onicofagia representada por un $40 \%$ de la muestra. Debemos mencionar que en nuestra muestra el valor para la onicofagia fue del $41 \%$ representada por 72 escolares. Debemos indicar que el número de escolares estudiado en el presente estudio fue mayor. 


\section{Bibliografía.}

Baidal, P. R. (15 de 06 de 2016). Control de ansiedad en niños con capacidades especiales. (V. Y. B., Entrevistador)

Boyer-Chu, L. (2007). Promoviendo la salud bucal infantil. Programa de Cuidado de Salud Infantil de California, 82.

Breinbauer, C. (2006). Fortaleciendo el desarrollo de niños con necesidades especiales: Introducción al Modelo DIR y la terapia Floortime o Juego Circular. Revista de la Asociación Peruana de Psicoterapia Psicoanalítica de Niños y Adolescentes, 11(1).

Cassy Christianson, O. (2009). Atención dental para niños con necesidades especiales - . Abilitypath.

Christianson, O. (2009). Atención dental para niños con necesidades especiales -. Abilitypath.

Cuenca, U. $\quad$ d. $\quad$ (s.f.). Dspace. Obtenido de http://dspace.ucuenca.edu.ec/bitstream/123456789/20533/1/Tesis.pdf

De la Teja-Ángeles, E., Durán-Gutiérrez, A., Espinosa-Victoria, L., \& Ramírez-Mayans, J. (2008). Manifestaciones estomatológicas de los trastornos sistémicos más frecuentes en el Instituto Nacional de Pediatría. Revisión de la literatura y estadísticas del instituto. Acta Pediatr Mex, 29(4), 189-99.

Frugone Zambra, R., \& Rodríguez, C. (2003). Bruxismo. Avances en Odontoestomatología, 19(3).

García, C., \& Sánchez, A. (2000). Clasificaciones de la OMS sobre discapacidad. Murcia: OMS.

Lewis M, B. J. (2011). Repetitive Behavior Disorders in Autism. . MRDD Research Reviews. .

Majluf, E., \& Vasquez Palomino, F. (2014). Retardo Mental "Rotondo Humberto". En A. Perales, Manual de Psiquiatría (Vol. 2da Edición). Buenos Aires: SISBI. Obtenido de http://sisbib.unmsm.edu.pe/bibvirtual/libros/psicologia/manual_psiquiatr\%C3\%ADa/cap-11.htm

Manzano, P. d. (2010). Patologia Bucal Prevalente en Ninos Excepcionales. Acta Odont Venez, 193-8.

Marulanda, J., Betancur, J. D., Espinoza, S., Gómez, J. L., \& Tapias, A. (2011). Salud oral en discapacitados. JMarulanda, 6.

Munoz, A. M. (2004). El sindrome de Down. Usal, 104.

Nualart-Grollmus , Z., Morales-Chavez, M., \& Silvestre-Donat, F. (2010). Periodontal Disease associated to systemic genetic disorders. Med Oral Patol Oral Cir Bucal., 12:E212-5.

Patricia Rodriguez, Susana Flores. (2013). Estrategias para contribuir con el desarrollo de la motricidad fina en niños de 4 a 5 años. Facultad de Psicología. Cuenca: Universidad de Cuenca.

Perez, M., Limeres, J., \& Fernandez, J. (2012). Manual de higiene oral para personas con discapacidad. Unidad de Pacientes Especiales. DEpartamento de Estomatologia. Universidad de SAntiago de COmpostela, 146.

Rosales C, J., Carvajal P, C., Del Valle A, C., Mendoza V, C., Riquelme L, I., \& Silva C, P. (2013). Higiene bucal en personas en situación de discapacidad - Manual para los cuidadores. Gobierno de Chile, 22. 
Tolleres, S. у. (2010). Universidad de Los Andes. Obtenido de http://estsocial.sld.cu/docs/Publicaciones/Indice\%20de\%20Higiene\%20Bucal.pdf

Zaman, A. R. (2007). Salud bucal para niños con discapacidades y necesidades especiales. California: Childcare Health Program. 